\title{
Research on a Nonlinear Robust Adaptive Control Method of the Elbow Joint of a Seven-Function Hydraulic Manipulator Based on Double-Screw-Pair Transmission
}

\author{
Gaosheng Luo, ${ }^{1}$ Jiawang Chen, ${ }^{2}$ and Linyi Gu${ }^{1}$ \\ ${ }^{1}$ State Key Laboratory of Fluid Power Transmission and Control, Zhejiang University, Hangzhou 310027, China \\ ${ }^{2}$ Ocean College, Zhejiang University, Hangzhou 310058, China \\ Correspondence should be addressed to Jiawang Chen; arwang@zju.edu.cn
}

Received 1 November 2013; Revised 19 March 2014; Accepted 8 April 2014; Published 26 June 2014

Academic Editor: Paulo Batista Gonçalves

Copyright (c) 2014 Gaosheng Luo et al. This is an open access article distributed under the Creative Commons Attribution License, which permits unrestricted use, distribution, and reproduction in any medium, provided the original work is properly cited.

\begin{abstract}
A robust adaptive control method with full-state feedback is proposed based on the fact that the elbow joint of a seven-function hydraulic manipulator with double-screw-pair transmission features the following control characteristics: a strongly nonlinear hydraulic system, parameter uncertainties susceptible to temperature and pressure changes of the external environment, and unknown outer disturbances. Combined with the design method of the back-stepping controller, the asymptotic stability of the control system in the presence of disturbances from uncertain systematic parameters and unknown external disturbances was demonstrated using Lyapunov stability theory. Based on the elbow joint of the seven-function master-slave hydraulic manipulator for the $4500 \mathrm{~m}$ Deep-Sea Working System as the research subject, a comparative study was conducted using the control method presented in this paper for unknown external disturbances. Simulations and experiments of different unknown outer disturbances showed that (1) the proposed controller could robustly track the desired reference trajectory with satisfactory dynamic performance and steady accuracy and that (2) the modified parameter adaptive laws could also guarantee that the estimated parameters are bounded.
\end{abstract}

\section{Introduction}

The elbow joint of a seven-function hydraulic manipulator with double-screw-pair transmission is shown in Figure 1 with the transmission model of a hydraulic-driving oscillating oil cylinder. The hydraulic-driving control system is known to be endowed with a strong nonlinearity [1], for which the system control is susceptible to the dead band of the servo valve and the spool friction [2], as well as unmodeled nonlinearity, such as spool abrasion and the leakage of the hydraulic system. Additionally, the system parameters of the hydraulic system are susceptible to the external environment during its working process; for example, the elastic modulus of the oil liquid is easily influenced by the external temperature and pressure. Furthermore, when the manipulator grasps a load with unknown weight for different operating tasks and at different postures, the elbow joint will also be subjected to unknown external interference and influenced by unknown additional inertial mass. During the movement of the underwater-operating manipulator, each of the joints exhibits different linear velocities and angular velocities, together with unknown hydrodynamic coefficients [3]; thus, the influences of seawater damping on each joint are also unknown.

In summary, the control system of an elbow joint of the seven-function hydraulic manipulator based on a doublescrew-pair transmission shows the following characteristics during its operation: (1) it is a strong nonlinear system; (2) the system parameters are unknown; (3) the system experiences unknown external disturbances.

The PD control method [3, 4], a linear control method that does not require a physical model, is typically used in conventional hydraulic systems; however, when PD control is directly used in nonlinear systems, the control performance will suffer extensive changes or even introduce instability to the system if the system parameters vary greatly or stabilize over a wide range of parameters [5]. 


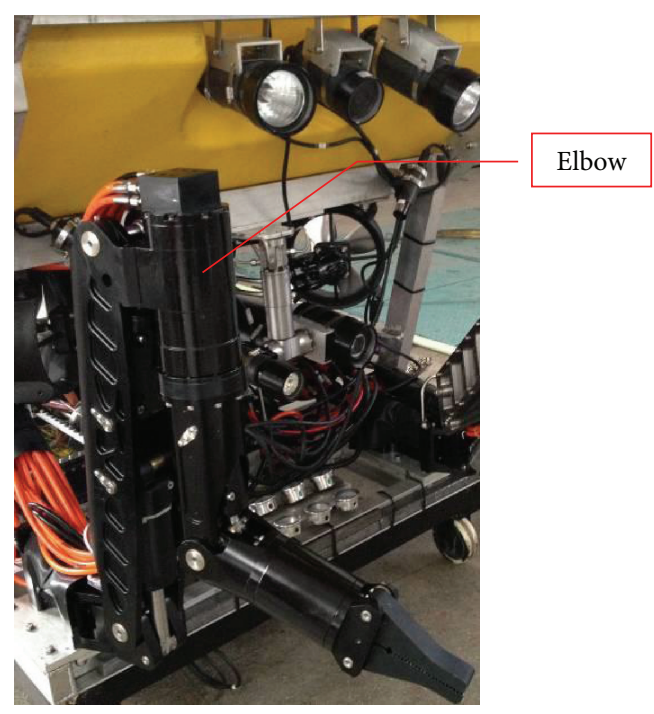

FIGURE 1: Seven-function hydraulic manipulator and its elbow.

Research has yielded numerous achievements in the development of the nonlinear position-control method of the manipulator joint [6-9]; nevertheless, these developments are aimed at controls without consideration of the actuator dynamics, and these control algorithms will no longer be applicable under the coupling of the dynamic state of the hydraulic-driving system and the elbow mechanical system if the dynamic state of the hydraulic actuator system is added.

However, the back-stepping technique, which can provide a systematic closed-loop construction by means of the Lyapunov function, can easily handle the complex coupled dynamics due to its specific design procedure. Benefiting from its ease of implementation and simple configuration, this control method has been widely used for various practical systems [10], such as marine vehicles [11], nonholonomic mechanical systems [12], and manipulators [13-15]. Conversely, a robust adaptive control method can be combined with the back-stepping technique to ensure the control precision and compensate for the lumped uncertainties.

Thus, the back-stepping technique combined with robust adaptive control method is adopted in this study to control the complex coupled dynamics of the hydraulic system and the elbow mechanical system. The back-stepping technique handles the coupled dynamics well, while the parameter uncertainties and unknown external slowly varying disturbances are effectively compensated for by using the robust adaptive method, leading to a satisfactory control performance.

This paper principally includes three parts. In the first part, the modeling and robust adaptive control methods of the elbow joint of the seven-function hydraulic manipulator with double-screw-pair transmission are described, along with a theoretical proof that the robust adaptive controller shows globally asymptotic stability. In the second and third parts, the validity of the proposed control method was verified using simulations and experiments for the elbow joint of the seven-function hydraulic manipulator of the $4500 \mathrm{~m}$ Deep-Sea Working System.

\section{Robust Adaptive Control Methods of the Elbow Joint of a Seven-Function Hydraulic Manipulator with Double-Screw-Pair Transmission}

\subsection{Modeling of the Elbow System of a Seven-Function} Hydraulic Manipulator with Double-Screw-Pair Transmission. A schematic diagram of the elbow system of a sevenfunction hydraulic manipulator with a double-screw-pair transmission is shown in Figure 2.

The system mainly consisted of the elbow body and the servo valve 7 , in which the former was principally composed of the angle sensor 1 , the elbow cylinder 2, the output shaft 3 , the outer screw pair 4, the piston 5, the inner screw pair 6 , and other accessories. The sensor, which was connected to the output shaft, was used to detect the rotational angle of output shaft 3 relative to elbow cylinder 4; piston 5 engages with cylinder body 2 via the outer screw pair 4 and with output shaft 3 via the inner screw pair 6 (the screw directions of the inner and the outer screw pairs were opposite). Piston 5 can undergo a displacement of $x_{L}$ inside cylinder body 1 in response to the oil pressure difference $P_{L}$ of its two ends; moreover, output shaft 3 can move along a rotational angle of $\theta$ by means of the outer screw pair 4 and the inner screw pair 6. In addition, the supply pressure of servo valve 7 is denoted by $P_{s}$, and the return pressure is denoted by $P_{R}$, with a coil input current of $i$.

The dynamical equation of the double-screw-pair transmission of the manipulator elbow is

$$
\tau=K_{T} A P_{L}
$$

where $\tau$ is the output torque of the elbow output shaft; $P_{L}=$ $P_{1}-P_{2}$ is the pressure difference between the two chambers of the oscillating oil cylinder in the elbow screw pair; $A$ is the effective acting area of piston 5 , which is a known positive constant; $K_{T}$, a known driving constant with a positive value, is the conversion coefficient for the hydraulic force and the output torque.

The dynamical equation of the manipulator elbow is

$$
I \ddot{\theta}+b \dot{\theta}=\tau+f
$$

where $\theta$ is the output oscillation angle of the elbow output shaft $3 ; I$ is the rotational inertia along elbow output shaft 3 , which is a positive load-associated slowly varying variable or invariant with an upper bound and an unknown actual value; $b$ is an unknown bounded damping coefficient, which is a positive quantity caused by the joint action of the hydraulic system damping and the external damping; $f$ is the unknown external invariable or slowly varying disturbing torque, such as the external load disturbing torque and the friction torque of the elbow screw pair transmission.

The flow continuity equation [2] of the elbow oscillating cylinder with double-screw-pair transmission is

$$
\frac{V_{t}}{4 \beta_{e}} \dot{P}_{L}=-A \dot{x}_{L}-C_{\mathrm{tm}} P_{L}+Q_{L},
$$

where $V_{t}$, a known quantity, is the sum of the total volume of the oscillating oil cylinder and that between the servo valve 


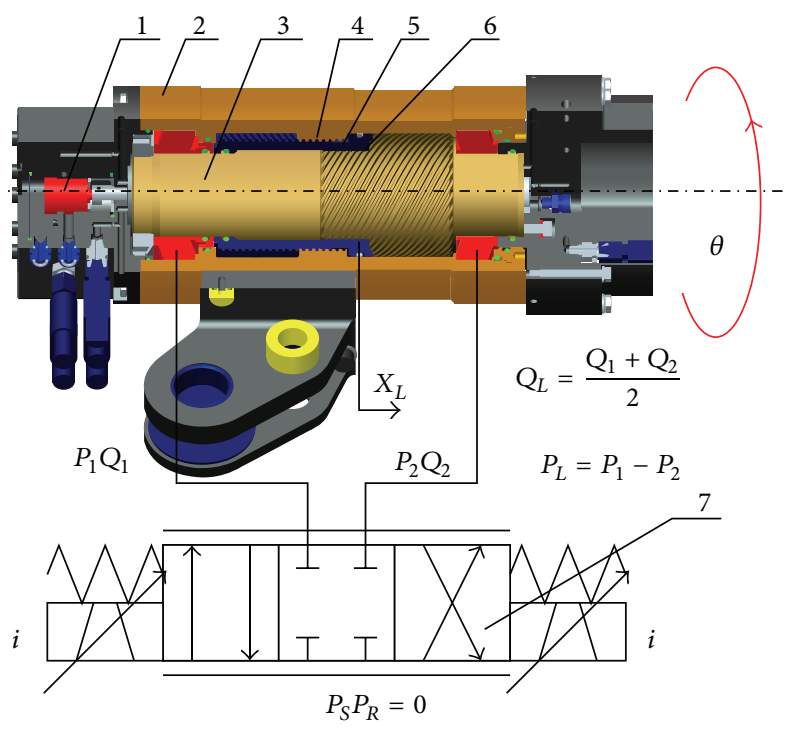

Figure 2: Hydraulic schematic diagram of the elbow system of a seven-function manipulator.

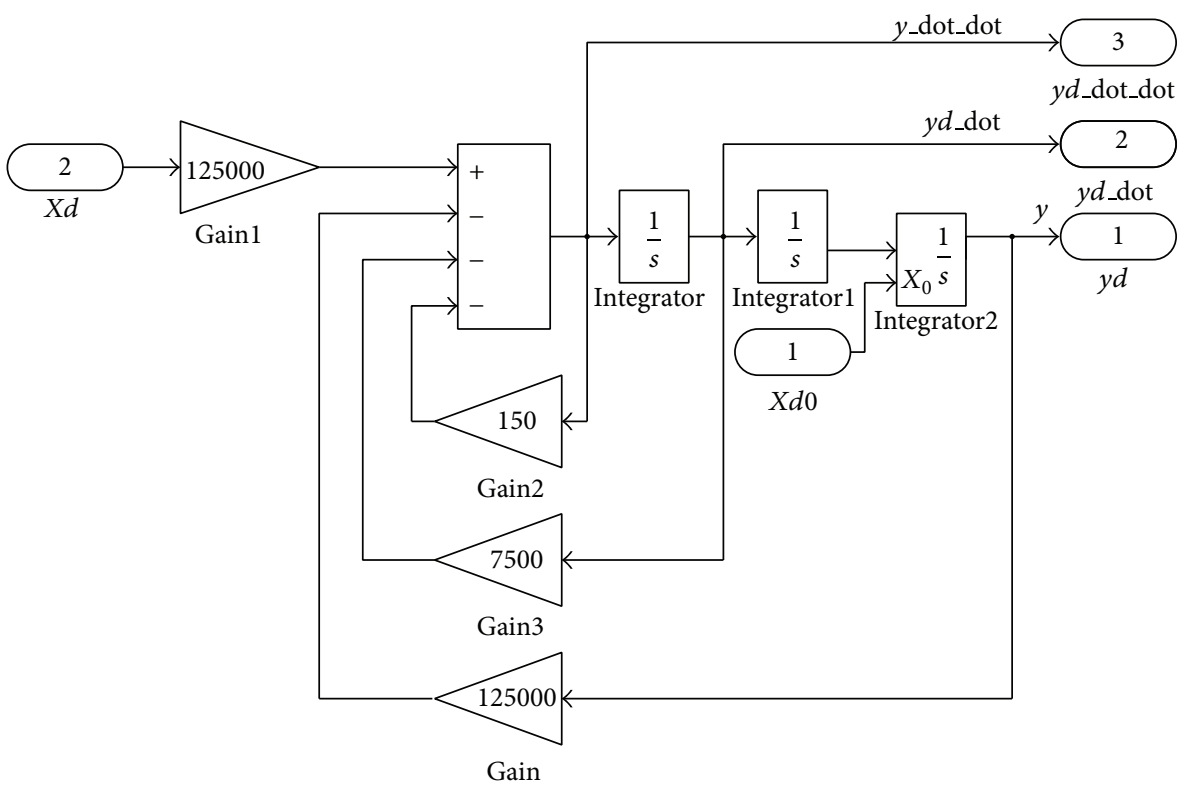

FIGURE 3: Schematic of the prefilter.

and the cylinder; $\beta_{e}$ is the effective elastic modulus of the hydraulic oil, which is a generally positive unknown slow variable and is susceptible to the external temperature and pressure; $C_{\mathrm{tm}}$ is the total leakage, which is sufficiently small to be ignored in the modeling process for the oscillating oil cylinder.

$x_{L}$ is the displacement of piston 5; from the structure of the double-screw-pair transmission, we could determine that its relationship with the rotational angle of output shaft 3 is

$$
x_{L}=K_{\theta} \theta \text {, }
$$

where $K_{\theta}$, a known positive constant value, is the proportionality coefficient between the displacement, $x_{L}$, of piston 5 and the oscillating angle, $\theta$, of output shaft 3 .
The pressure-flow equation [2] of the servo valve is

$$
Q_{L}=K_{q} x_{v} \sqrt{P_{s}-\operatorname{sgn}\left(x_{v}\right) P_{L}}
$$

where $Q_{L}$ is the flow through the valve, which is a function of the spool displacement, $x_{v} . K_{q}=C_{d} w \sqrt{1 / \rho}$ is a known parameter of the servo valve, $C_{d}$ is the flow coefficient, $w$ is the port area of the servo valve, and $\rho$ is the density of the oil liquid.

The equation of the spool displacement, $x_{v}$, could be expressed as a first-order inertial system:

$$
\tau_{v} \dot{x}_{v}=-x_{v}+K_{i} i,
$$


where $K_{i}$, a known quantity, is the proportionality coefficient of the input current.

The current-voltage equation of the proportional amplifier board is

$$
\tau_{i} \dot{i}=-i+K_{i} u
$$

where $i$ and $u$ are the coil current of the servo valve and the input voltage of the proportional amplifier board, respectively, and $K_{v}$, a known quantity, is the voltage proportionality coefficient.

$\tau_{v}$ and $\tau_{i}$ are time constants that are much smaller than that of the entire system; consequently, the dynamics of these two components are negligible, which allows (7) to be simplified to a direct proportional component; that is,

$$
x_{v}=K_{u} u
$$

where $K_{u}=K_{v} K_{i}$.

The following hypotheses are indispensable in the controller design.

Hypothesis 1. The reference trajectory is continuously differentiable, and its third derivatives, $\dot{\theta}_{d}, \ddot{\theta}_{d}$, and $\ddot{\theta}_{d}$, exist.

Hypothesis 2. The velocity of the elbow joint is bounded.

Hypothesis 3. The rotational inertia, $I$, the damping coefficient, $b$, the perturbation, $f$, and the characteristic modulus of the hydraulic oil, $\beta_{e}$, are all slowly changing variables and are bounded, and the sign of the elastic modulus, $\beta_{e}$, is known.

2.2. Robust Adaptive Control Method Study of the Elbow Joint with Double-Screw-Pair Transmission. Substituting (1) and (4) into (3) yields the dynamic equation of the entire system:

$$
\begin{gathered}
I \ddot{\theta}+b \dot{\theta}=\tau+f \\
\dot{\tau}=\frac{4 \beta_{e}}{V_{t}} K_{T} A\left(-A K_{\theta} \dot{\theta}+Q_{L}\right) .
\end{gathered}
$$

Here, the design method of the back-stepping controller was used to design the robust adaptive controller.

Step 1. Define $\left[\begin{array}{ll}x_{1} & x_{2}\end{array}\right]^{T}=\left[\begin{array}{ll}\theta & \dot{\theta}\end{array}\right]^{T}$; the system of (9) could then be transformed into

$$
\begin{gathered}
\dot{x}_{1}=x_{2}, \\
I \dot{x}_{2}+b x_{2}=\tau+f \\
\dot{\tau}=\frac{4 \beta_{e}}{V_{t}} K_{T} A\left(-A K_{\theta} x_{2}+Q_{L}\right) .
\end{gathered}
$$
lows.

The following controlled variables were defined as fol-

The tracing error:

$$
\widetilde{\theta}=x_{1}-\theta_{d}
$$

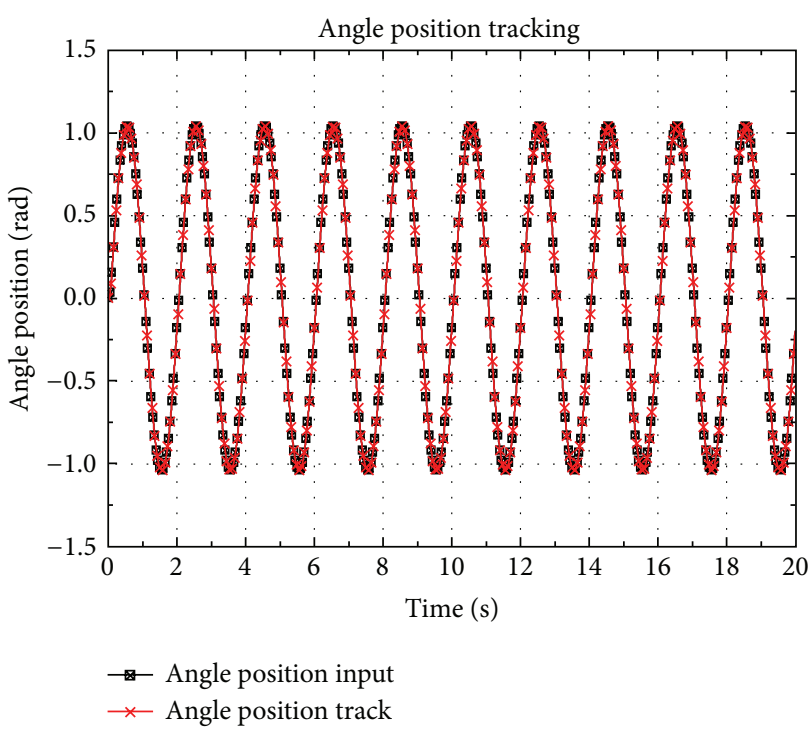

FIgURE 4: Tracking performance with a $100 \mathrm{Nm}$ outer disturbance.

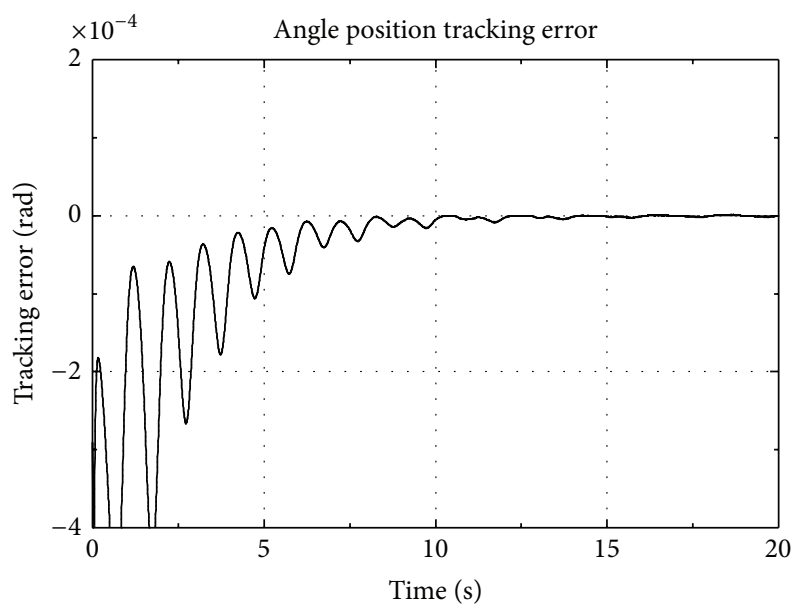

FIGURE 5: Tracking error with a $100 \mathrm{Nm}$ outer disturbance.

The relative reference speed:

$$
\dot{z}=\dot{\theta}_{d}-\lambda \tilde{\theta}
$$

The relative reference acceleration:

$$
\ddot{z}=\dot{\theta}_{d}-\lambda \dot{\widetilde{\theta}}
$$

The relative reference speed error:

$$
s=x_{2}-\dot{z}=\dot{\widetilde{\theta}}+\lambda \tilde{\theta} .
$$

Equation (16) for the relative reference speed error is actually a filter with the input of $s$ and the output of $\tilde{\theta}$; if $\lambda$ is properly chosen to stabilize the system, $\widetilde{\theta}$ will converge to 0 at the exponential convergence of $\lambda$ when $s=0$. used:

For (11), the following expected control law, $\tau_{d}$, of $\tau$ is

$$
\tau_{d}=\widehat{I} \ddot{z}+\widehat{b} \dot{z}-\widehat{f}-K_{D} s,
$$



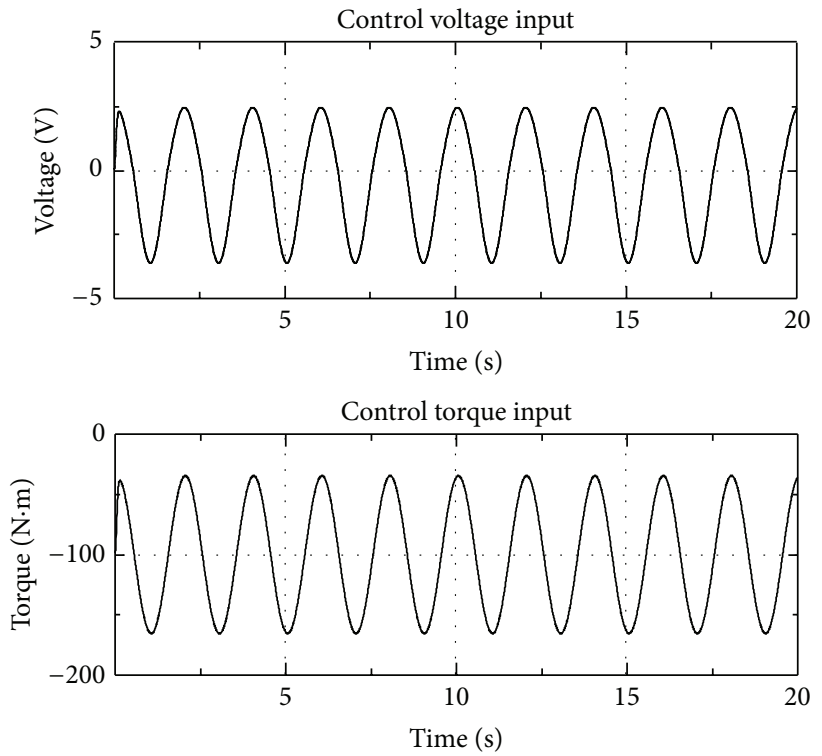

FIgURE 6: Control inputs with a $100 \mathrm{Nm}$ outer disturbance.

where $\widehat{I}, \widehat{b}$, and $\widehat{f}$ are the estimated parameters of $I, b$, and $f$, respectively; $K_{D}$ is the design quantity of the controller, which is a positive constant coefficient.

Thus, $\tau$ is defined as

$$
\tau=\tau_{d}+\tilde{\tau}
$$

where $\widetilde{\tau}$ is the error between the actual control, $\tau$, and the expected control, $\tau_{d}$.

Substituting (17) and (18) into (12) yields the following:

$$
I \dot{x}_{2}+b x_{2}=\widehat{I} \ddot{z}+\widehat{b} \dot{z}-\widehat{f}-K_{D} s+\tilde{\tau}+f .
$$

Substituting (16) into (19) then yields the following:

$$
\begin{aligned}
I \dot{s}+b s= & (\widehat{I}-I) \ddot{z}+(\widehat{b}-b) \dot{z}-(\widehat{f}-f) \\
& -K_{D} s+\widetilde{\tau}+f=\widetilde{I} \ddot{z}+\widehat{b} z-\widetilde{f}-K_{D} s+\widetilde{\tau},
\end{aligned}
$$

where $\widetilde{I}=\widehat{I}-I, \widetilde{b}=\widehat{b}-b$, and $f=\widehat{f}-f$ are the parameter estimation errors.

The Lyapunov function of (20) is defined as follows:

$$
V_{1}^{\prime}=\frac{1}{2}\left[I s^{2}+\Gamma_{I}^{-1} \widetilde{I}^{2}+\Gamma_{b}^{-1} \widetilde{b}^{2}+\Gamma_{f}^{-1} \widetilde{f}^{2}\right]
$$

Substituting (20) into the derivate of (21) with respect to time yields the following:

$$
\begin{aligned}
\dot{V}_{1}^{\prime}= & s I \dot{s}+\Gamma_{I}^{-1} \dot{\widetilde{I}}+\Gamma_{b}^{-1} \tilde{b} \dot{\widetilde{b}}+\Gamma_{f}^{-1} \tilde{\tilde{f}} \dot{\tilde{f}} \\
= & -b s^{2}-K_{D} s^{2}+\widetilde{I}\left(s \ddot{z}+\Gamma_{I}^{-1} \dot{\widetilde{I}}\right) \\
& +\tilde{b}\left(s \dot{z}+\Gamma_{b}^{-1} \dot{\widetilde{b}}\right)+\tilde{f}\left(-s+\Gamma_{f}^{-1} \dot{\tilde{f}}\right),
\end{aligned}
$$

where $\Gamma_{I}, \Gamma_{b}$, and $\Gamma_{f}$ are the corresponding estimation gains, which are all positive constants.
The following parameter estimation law was applied:

$$
\begin{gathered}
\dot{\widetilde{I}}=\dot{\widehat{I}}=-\Gamma_{I} s \ddot{z}, \\
\dot{\widetilde{b}}=\dot{\hat{b}}=-\Gamma_{b} s \dot{z}, \\
\dot{\widetilde{f}}=\dot{\hat{f}}=\Gamma_{f} s .
\end{gathered}
$$

Substituting (23) into (22) yields

$$
\dot{V}_{1}^{\prime}=-b s^{2}-K_{D} s^{2}+s \tilde{\tau} .
$$

When $\tilde{\tau}=0$, that is, the actual controlled variable $\tau$ is consistent with the expected virtual control law $\tau_{d}$, the following holds true:

$$
\dot{V}_{1}^{\prime}=-b s^{2}-K_{D} s^{2} \leq 0 .
$$

The LaSalle-Yoshizawa [16] theorem states that $\widehat{I}, \widehat{b}$, and $\widehat{f}$ are all bounded; we could then obtain the following from Slotine and Li for $s \rightarrow 0$ [17]:

$$
\begin{aligned}
& \tilde{\theta} \longrightarrow 0, \\
& \dot{\tilde{\theta}} \longrightarrow 0 .
\end{aligned}
$$

Step 2. In this step, the corresponding control law must be designed to force $\widetilde{\tau}=0$, which could be obtained from (18):

$$
\tilde{\tau}=\tau-\tau_{d}
$$

Substituting (12) into the derivative of both sides of (27) with respect to time yields the following:

$$
\dot{\tau}=\frac{4 \beta_{e}}{V_{t}} K_{T} A\left(-A K_{\theta} x_{2}+Q_{L}\right)-\dot{\tau}_{d}
$$


Equations (5) and (8) indicate that $Q_{L}$ is directly associated with the actual control input, $u$, without any other dynamics between them. As a consequence, $Q_{L}$ could be treated as the actual control input.

Let

$$
\alpha=\beta_{e}, \quad \vartheta=\frac{1}{\alpha}, \quad \widehat{\vartheta}=\frac{1}{\widehat{\alpha}}, \quad \widetilde{\vartheta}=\widehat{\vartheta}-\vartheta,
$$

where $\widehat{\alpha}$ and $\widehat{\vartheta}$ are the estimations of $\alpha$ and $\vartheta$, respectively, and $\widetilde{\vartheta}$ is the estimation error of $\vartheta$. follows:

Define the expected controlled variable, $Q_{L d}$, of $Q_{L}$ as

$$
Q_{L d}=A K_{\theta} x_{2}+\widehat{\vartheta} \frac{V_{t}}{4 \beta_{e} K_{T} A}\left(\dot{\tau}_{d}-s-\lambda_{3} \widetilde{\tau}\right),
$$

where $\lambda_{3}$ is a positive control constant.

Substituting (30) into (28) then yields the following:

$$
\begin{aligned}
\dot{\tilde{\tau}} & =\alpha \widetilde{\theta}\left(\dot{\tau}_{d}-s-\lambda_{3} \widetilde{\tau}\right)-\dot{\tau}_{d} \\
& =\alpha(\vartheta+\widetilde{\vartheta})\left(\dot{\tau}_{d}-s-\lambda_{3} \widetilde{\tau}\right)-\dot{\tau}_{d} \\
& =-s-\lambda_{3} \widetilde{\tau}+\alpha \widetilde{\vartheta}\left(\dot{\tau}_{d}-s-\lambda_{3} \widetilde{\tau}\right),
\end{aligned}
$$

where the value of $\beta_{e}$ is known; the Lyapunov function of the entire system is defined as follows:

$$
\begin{aligned}
V^{\prime} & =V_{1}^{\prime}+\frac{1}{2} \widetilde{\tau}^{2}+\frac{1}{2} \frac{|\alpha|}{\gamma} \widetilde{\vartheta}^{2} \\
& =\frac{1}{2}\left(I s^{2}+\Gamma_{I}^{-1} \widetilde{I}^{2}+\Gamma_{b}^{-1} \widetilde{b}^{2}+\Gamma_{f}^{-1} \widetilde{f}^{2}+\widetilde{\tau}^{2}+\frac{|\alpha|}{\gamma} \widetilde{\vartheta}^{2}\right),
\end{aligned}
$$

where $\gamma$ is a positive control constant.

Substituting (23) and (31) into the derivative of both sides of (32) with respect to time yields the following:

$$
\begin{aligned}
\dot{V}^{\prime}= & -\left(K_{D}+b\right) s^{2}+s \tilde{\tau}+\tilde{\tau} \dot{\tau}+\frac{|\alpha|}{\gamma} \tilde{\vartheta} \dot{\tilde{\vartheta}} \\
= & -\left(K_{D}+b\right) s^{2}+s \tilde{\tau}-s \tilde{\tau}-\lambda_{3} \widetilde{\tau}^{2} \\
& +\widetilde{\tau} \alpha \widetilde{\vartheta}\left(\dot{\tau}_{d}-s-\lambda_{3} \tilde{\tau}\right) \frac{|\alpha|}{\gamma} \tilde{\vartheta} \dot{\tilde{\vartheta}} \\
= & -\left(K_{D}+b\right) s^{2}-\lambda_{3} \tilde{\tau}^{2} \\
& +|\alpha| \widetilde{\vartheta}\left[\tilde{\tau} \operatorname{sgn}(\alpha)\left(\dot{\tau}_{d}-s-\lambda_{3} \tilde{\tau}\right)+\frac{1}{\gamma} \dot{\tilde{\vartheta}}\right] .
\end{aligned}
$$

The parameter estimation law of $\vartheta$ is defined as follows:

$$
\dot{\tilde{\vartheta}}=\dot{\bar{\vartheta}}=-\gamma \widetilde{\tau} \operatorname{sgn}(\alpha)\left(\dot{\tau}_{d}-s-\lambda_{3} \tilde{\tau}\right) .
$$

Substituting (34) into (33) yields

$$
\dot{V}^{\prime}=-\left(K_{D}+b\right) s^{2}-\lambda_{3} \tilde{\tau}^{2} \leq 0 .
$$

The LaSalle-Yoshizawa [16] theorem indicates that

$$
s \longrightarrow 0, \quad \tilde{\tau} \longrightarrow 0 .
$$

According to Slotine and Li [17], we obtain the following for $s \rightarrow 0$ :

$$
\tilde{\theta} \longrightarrow 0, \quad \dot{\tilde{\theta}} \longrightarrow 0
$$

If we define $\bar{e}^{T}=\left[\begin{array}{llllll}s & \widetilde{I} & \widetilde{b} & \tilde{f} & \widetilde{\tau} & \widetilde{\vartheta}\end{array}\right]^{T}$, then

$$
V^{\prime}=\frac{1}{2} \bar{e}^{T}\left[\begin{array}{cccccc}
I & & & & & \\
& \Gamma_{I}^{-1} & & & & \\
& & \Gamma_{b}^{-1} & & & \\
& & & \Gamma_{f}^{-1} & & \\
& & & & 1 & \\
& & & & & \frac{|\alpha|}{\gamma}
\end{array}\right] \bar{e}
$$

Because the derivative of the Lyapunov function is negative definite, $V^{\prime}(t) \leq V^{\prime}(0)$ and

$$
\frac{1}{2} \beta_{\min }^{\prime}\|\overline{e(t)}\|^{2} \leq V^{\prime}(t) \leq V^{\prime}(0) \leq \beta_{\max }^{\prime}\|\overline{e(0)}\|,
$$

where

$$
\begin{aligned}
& \beta_{\min }^{\prime}=\underline{\delta}\left(\left[\begin{array}{cccccc}
I & & & & & \\
& \Gamma_{I}^{-1} & & & & \\
& & \Gamma_{b}^{-1} & & & \\
& & & \Gamma_{f}^{-1} & & \\
& & & & 1 & \\
& & & & \frac{|\alpha|}{\gamma}
\end{array}\right]\right), \\
& \beta_{\max }^{\prime}=\bar{\delta}\left(\left[\begin{array}{llllll}
I & & & & & \\
& \Gamma_{I}^{-1} & & & & \\
& & \Gamma_{b}^{-1} & & & \\
& & & \Gamma_{f}^{-1} & & \\
& & & & 1 & \\
& & & & \frac{|\alpha|}{\gamma}
\end{array}\right]\right),
\end{aligned}
$$

where $\underline{\delta}$ and $\bar{\delta}$ are the minimum and maximum characteristic roots of the matrix, respectively [18]. Therefore, $\widetilde{I}, \widetilde{b}, \widetilde{f}, \widetilde{\tau}$, and $\widetilde{\vartheta}$ are all bounded.

When the actual required flow, $Q_{L d}$, is determined using (30), we obtain $Q_{L d}=K_{q} x_{v} \sqrt{P_{s}-\operatorname{sgn}\left(x_{v}\right) P_{L}}$ from the flow equation (5), wherein the symbol of the input $x_{v}$ is the same as that of $Q_{L d}$; thus,

$$
x_{v}=\left(K_{q} \sqrt{P_{s}-\operatorname{sgn}\left(Q_{L d}\right) P_{L}}\right)^{-1} Q_{L d} .
$$

Substituting (41) into (8) yields the following:

$$
u=\left(K_{u} K_{q} \sqrt{P_{s}-\operatorname{sgn}\left(Q_{L d}\right) P_{L}}\right)^{-1} Q_{L d} .
$$

Theorem 1. With the control input of (17), (30), and (42) and the parameter estimation law of (23) and (34), the elbow hydraulic control system of the manipulator is globally asymptotical stable. 

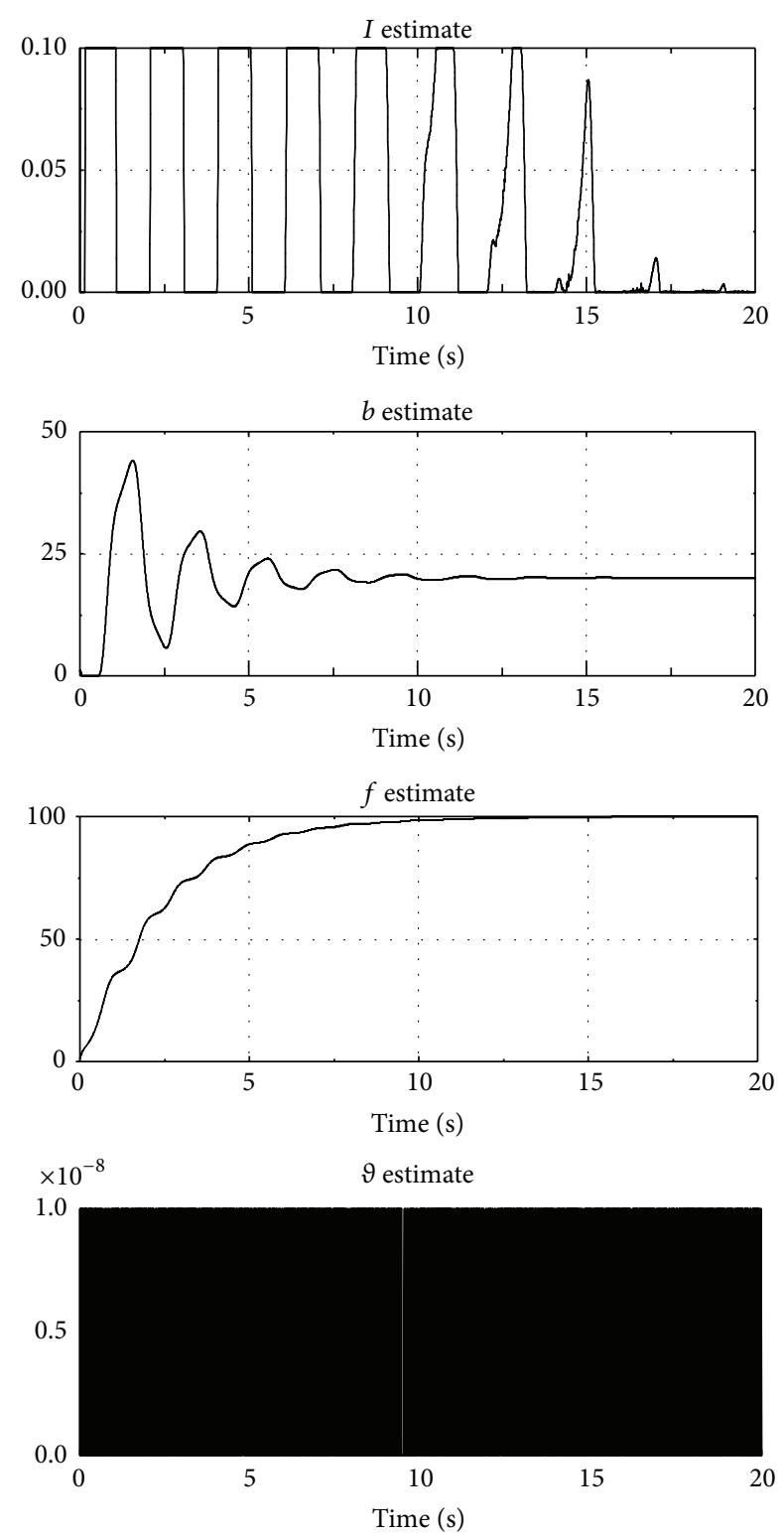

FIGURE 7: Estimates of parameters with a $100 \mathrm{Nm}$ outer disturbance.

\section{Simulation Study of a Robust Adaptive Control Method of the Elbow Joint of a Seven-Function Hydraulic Manipulator with Double-Screw-Pair Transmission}

To validate the proposed control method described in this paper, a simulation study was conducted that focused on the slave elbow joint of the seven-function master-slave hydraulic manipulator system for the $4500 \mathrm{~m}$ Deep-Sea Working System.

The nonlinear simulation model of the hydraulic manipulator elbow was established in Matlab/Simulink using the system parameters in Table 1 and the control system simulation parameters in Table 2 for the simulation. The parameters in Table 1 were based on the actual parameters of the elbow and were fixed quantities, whereas those in Table 2 were the simulation parameters and could be adjusted based on the actual need.

The system equations (10), (11), and (12) indicate that the elbow control system of the hydraulic manipulator is a three-order system; thus, a prefilter could be used to generate the third derivative of the input signal during the control law design or during actual use, and three inertial filters in series with the time constant of $20 \mathrm{~ms}$ were used, as shown in Figure 3.

Parameter estimation is susceptible to other external unknown disturbances, which will then induce the integrator saturation of the estimator $[19,20]$, resulting in system instability in accordance with the range of the actual parameters; consequently, the parameter range must be defined for the adaptive parameter estimation. Equation (43), a parameter estimation example of $I$, is based on a method of the modified parameter adaptive law, and the same method could be applied to the modification of the remaining estimations of the parameters:

$$
\dot{\vec{I}}=\dot{\vec{I}}= \begin{cases}0 & \text { if } \widehat{I}=I_{\max },-\Gamma_{I} s \ddot{z}>0, \\ -\Gamma_{I} s \ddot{z} & \text { other situations, } \\ 0 & \text { if } \widehat{I}=I_{\min },-\Gamma_{I} s \ddot{z}<0 .\end{cases}
$$

To verify the effect of the parameter uncertainty on the control system, an outer disturbing torque of $100 \mathrm{Nm}$ was simulated.

Figures 4 and 5 indicate that the robust adaptive controller of the elbow joint of a seven-function hydraulic manipulator could favorably track the control input with a small tracking error. Moreover, it could maintain its strong tracking performance at larger variations of the outer disturbance; that is, the controller was robust in response to unknown parameter changes, and the system correspondingly varied only in the control input (Figure 6) and the parameter estimation (Figure 7), wherein the parameter estimations were all bounded.

\section{Experiment on the Robust Adaptive Controller of the Elbow Joint of a Seven- Function Hydraulic Manipulator with Double-Screw-Pair Transmission}

A P4 processor operating at a frequency of $2.8 \mathrm{GHz}$ and with a NI 6229 PCI data acquisition card and the real-time operating system Matlab XPC were used in the experiment, as shown in Figure 8. In this figure, the left upper picture shows the manipulator, the right upper picture shows the proportional valve and the amplifier board, and the right lower corner shows the host running the real-time system. The controller generated in the simulation verification described in the previous section could be downloaded directly to the realtime kernel to run on XPC with this experimental platform.

A Wandfluh type directional 4/3-way proportional valve NG3-Mini was used, which was characterized by high resolution, low hysteresis $(\leq 5 \%)$, and a wet proportional electromagnet. 


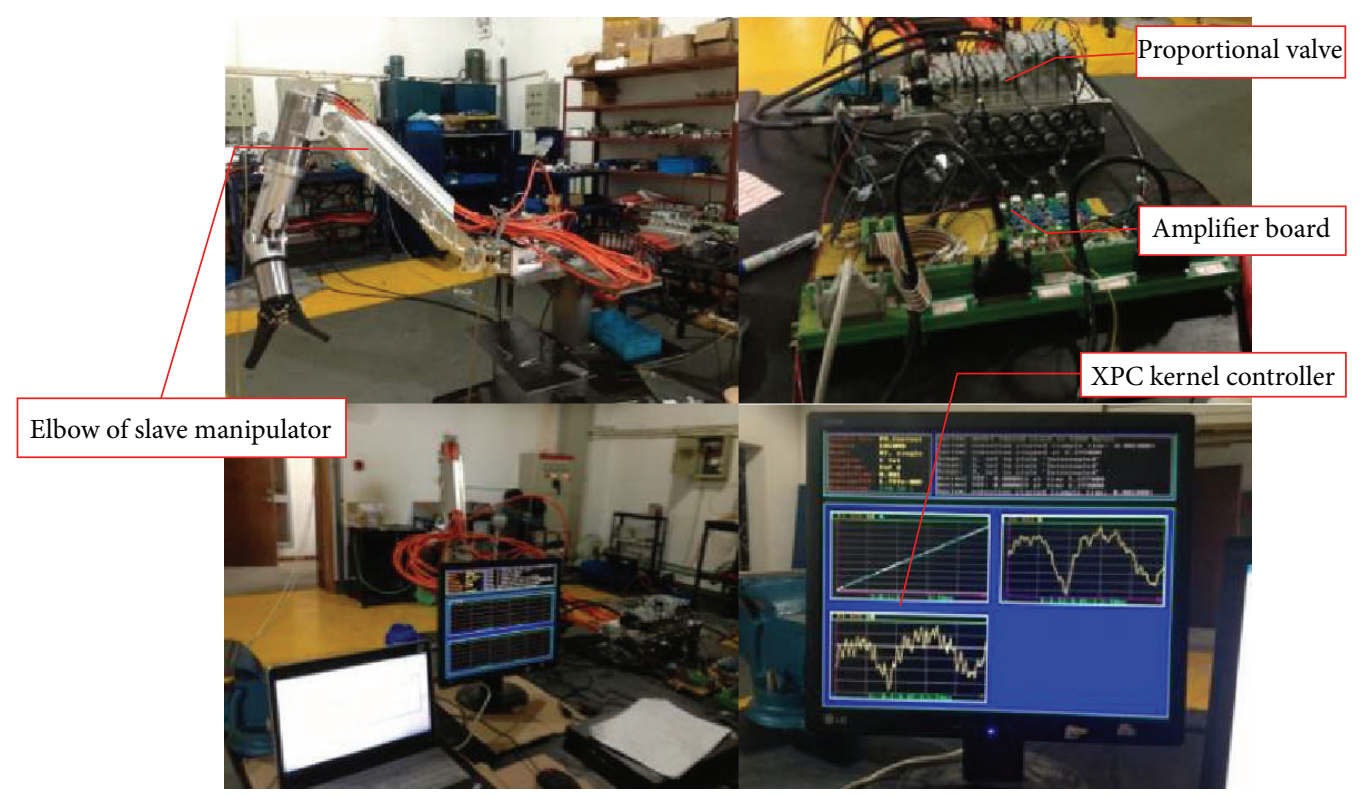

FIGURE 8: Experimental equipment of the elbow robust adaptive control system.

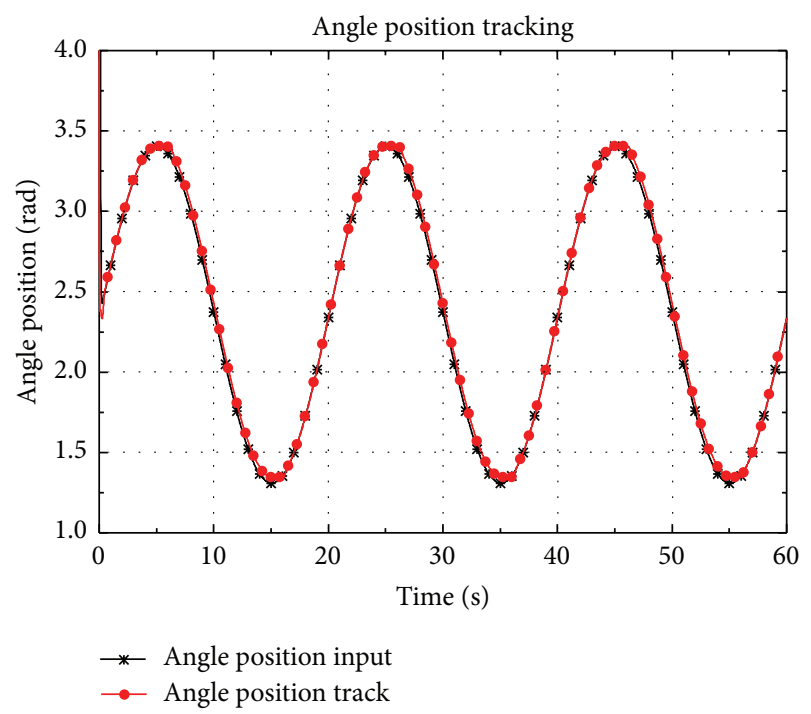

FIgURE 9: Tracking performance without a payload.

The system parameters of the elbow joint of the hydraulic manipulator are listed in Table 1, and the controller parameters are listed in Table 3.

Because the actual elbow joint was not equipped with an angular velocity sensor, the angular velocity was determined via the differentiation of the position. Nevertheless, the angular velocity obtained as such was easily affected by noise pollution, which would then influence the control effect.

The experiment was conducted in two steps: (1) the actuator did not grasp an object at the claw end, and the resulting experimental curves are shown in Figures 9, 10, 11, and 12; (2) the actuator at the claw end grasped an object $30 \mathrm{~kg}$ in mass with a certain eccentricity to the rotary shaft

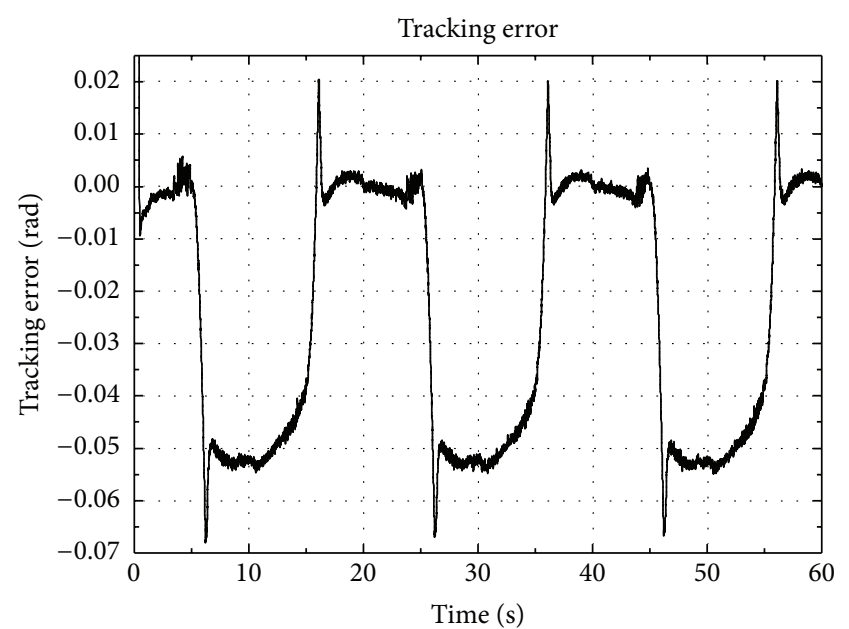

Figure 10: Tracking error without a payload.

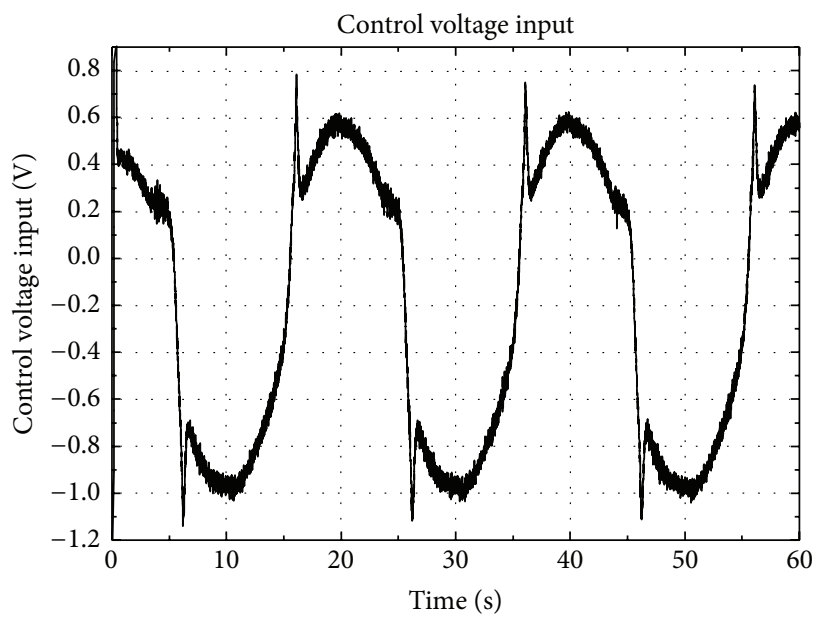

FIGURE 11: Control voltage input without a payload. 

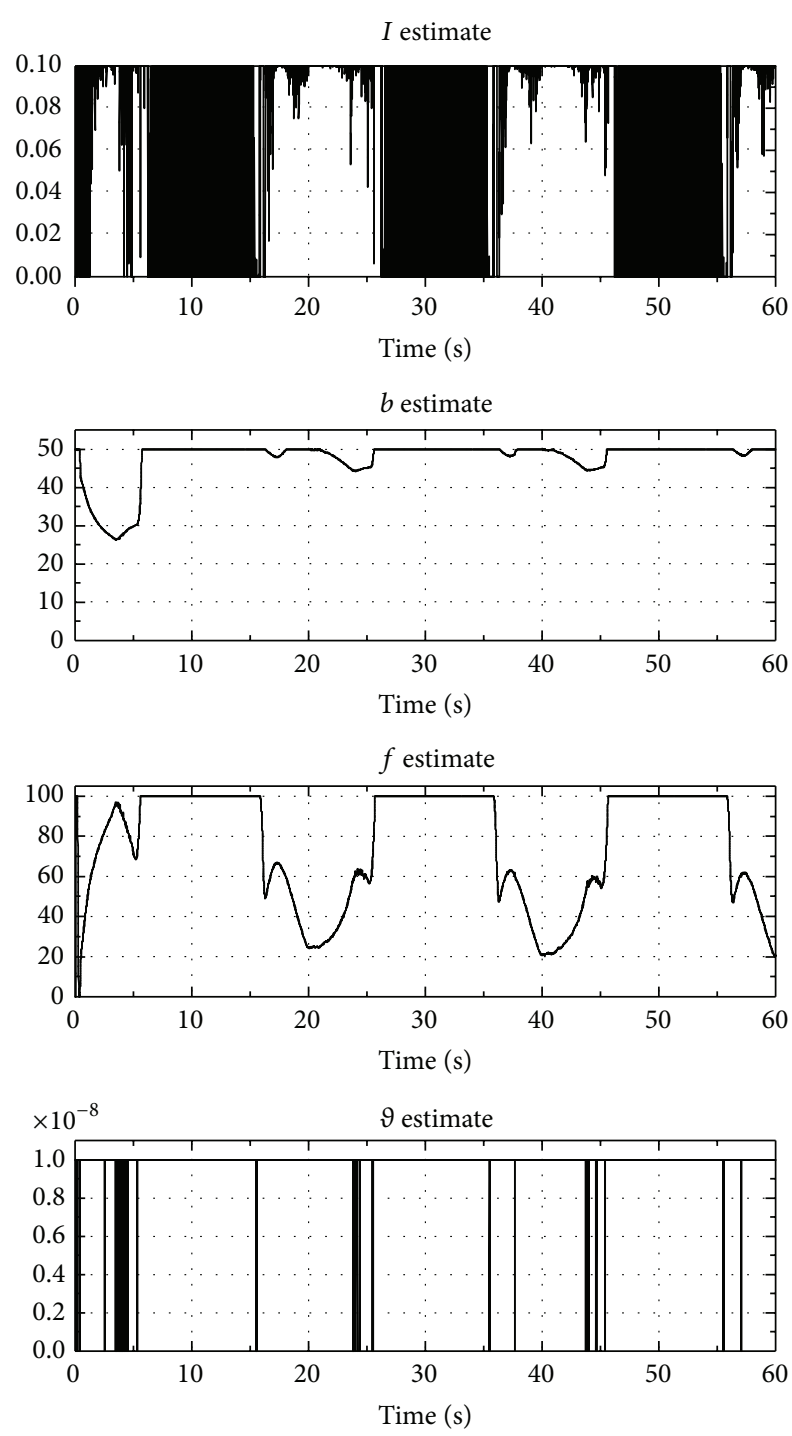

FIGURE 12: $I, b, f, \vartheta$ parameter estimates without a payload.

of the wrist, as shown in Figure 13. The experimental curves are shown in Figures 14, 15, 16, and 17.

Figures 9, 10, 14, and 15 indicated that the robust adaptive controller of the elbow joint of the double-screwdriving hydraulic manipulator showed favorable convergence properties, with a very small tracking error. When a $30 \mathrm{~kg}$ payload was applied as the outer disturbance, the controller's performance exhibited almost no change; that is, it exhibited good robustness. Figures 12 and 17 indicated that the estimated parameters were bounded, while the $I$ parameter estimator and the $\vartheta$ parameter estimator exhibited very serious switching phenomena and saturation phenomena. In the actual application, one can appropriately enlarge the estimation range of these estimators. In addition, Figures 10 and 15 indicate that the tracking error fluctuated and jumped when switching during the motion process of the elbow joint from the largest angle to the smallest angle, and this tracking error was primarily due to the meshing clearance of the double screw structure of the elbow driver.

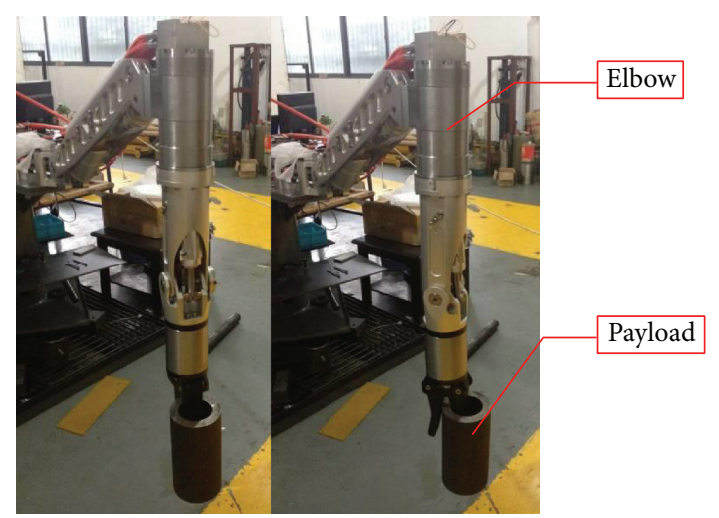

FIGURE 13: Manipulator grasping a $30 \mathrm{~kg}$ eccentric payload.

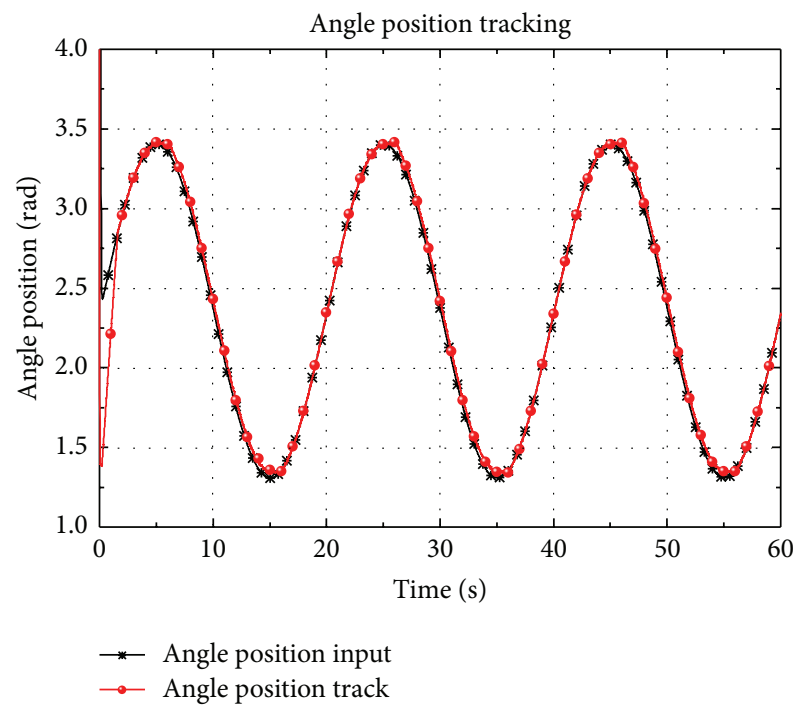

FIGURE 14: Tracking performance with a $30 \mathrm{~kg}$ eccentric payload.

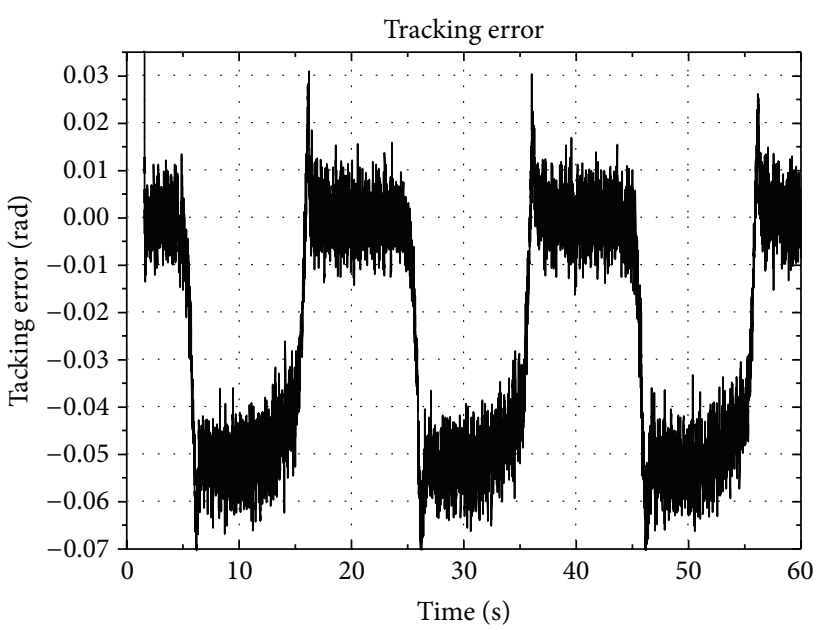

FIGURE 15: Tracking error with a $30 \mathrm{~kg}$ eccentric payload. 


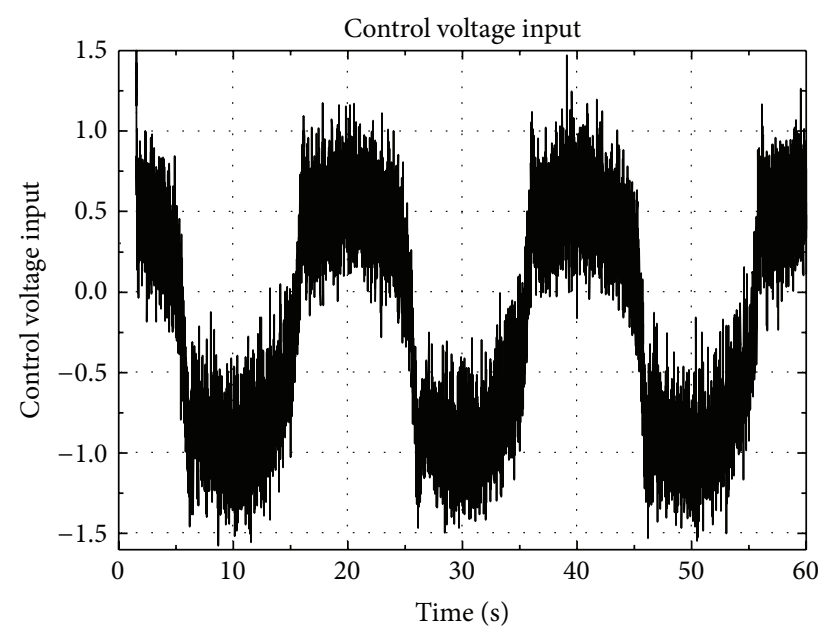

FIGURE 16: Control voltage input with a $30 \mathrm{~kg}$ eccentric payload.
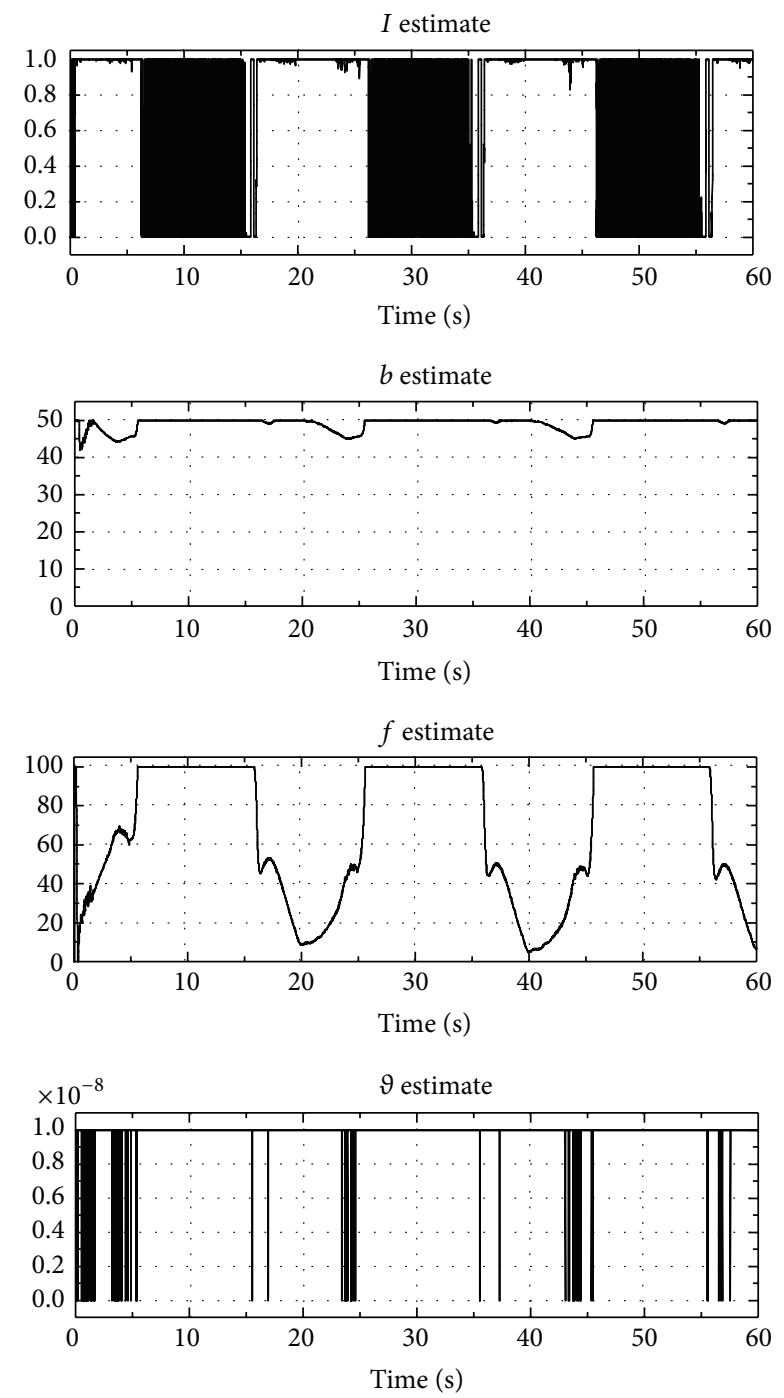

Figure 17: $I, b, f, \vartheta$ parameter estimates with a $30 \mathrm{~kg}$ eccentric payload.
TABLE 1: Parameters of the elbow hydraulic system.

\begin{tabular}{lc}
\hline Parameters & Values \\
\hline$I / \mathrm{kg} \cdot \mathrm{m}^{2}$ & 0.022 \\
$A / \mathrm{m}^{2}$ & 0.00481 \\
$\beta_{e} / \mathrm{N} / \mathrm{m}^{2}$ & $7.0 \times 10^{8}$ \\
$P_{s} / \mathrm{N} / \mathrm{m}^{2}$ & $1.0 \times 10^{7}$ \\
$i / \mathrm{mA}$ & $0 \sim 550$ \\
$V_{t} / \mathrm{m}^{3}$ & $7.104 \times 10^{-6}$ \\
$f / \mathrm{Nm}$ & 50 \\
$K_{T} / \mathrm{m}$ & 0.0078 \\
$K_{u} / \mathrm{mA} / \mathrm{V}$ & 110 \\
$K_{q} / \mathrm{m}^{3} /\left(\sqrt{\mathrm{N} / \mathrm{m}^{2}} \cdot \mathrm{mA} \cdot \mathrm{s}\right)$ & $1.852 \times 10^{-10}$ \\
$b / \mathrm{Nm} / \mathrm{rad} / \mathrm{s}$ & 20 \\
$K_{\theta} / \mathrm{m} / \mathrm{rad}$ & 0.01042 \\
\hline
\end{tabular}

TABLE 2: Emulation parameters of the elbow controller.

\begin{tabular}{lc}
\hline Parameters & Values \\
\hline$\lambda$ & 200 \\
$\Gamma_{I}$ & 500 \\
$\Gamma_{b}$ & 500 \\
$\Gamma_{f}$ & 500 \\
$\gamma$ & 500 \\
$K_{D}$ & 900 \\
$\lambda_{3}$ & 250 \\
$I_{\max }$ & 1.0 \\
$I_{\min }$ & 0.0001 \\
$b_{\max }$ & 50 \\
$b_{\min }$ & 0 \\
$f_{\max }$ & 100 \\
$f_{\min }$ & 0.001 \\
\hline
\end{tabular}

\section{Conclusion}

(1) In accordance with the hydraulic system dynamics of the manipulator elbow joint and the fluid flow continuity equation, a nonlinear robust adaptive controller based on full-state feedback was established using both the adaptive back-stepping control technology and Lyapunov stability theory. Furthermore, the closed-loop system was theoretically demonstrated to achieve globally asymptotic stability and the estimated parameters were shown to be bounded.

(2) The controller designed was applied to the control of the elbow joint of a seven-function master-slave hydraulic manipulator system for the $4500 \mathrm{~m}$ DeepSea Working System; the favorable tracking performance and robustness of the control system were verified via comparative studies of simulations and experiments.

(3) The method proposed in this paper could also be applied to the hydraulic control systems of valvecontrolled cylinders and valve-controlled motors. 
TABLE 3: Experimental parameters of the elbow controller.

\begin{tabular}{lc}
\hline Parameters & Values \\
\hline$\lambda$ & 20 \\
$\Gamma_{I}$ & 500 \\
$\Gamma_{b}$ & 500 \\
$\Gamma_{f}$ & 500 \\
$\gamma$ & 500 \\
$K_{D}$ & 500 \\
$\lambda_{3}$ & 200 \\
$I_{\max }$ & 1.0 \\
$I_{\min }$ & 0.0001 \\
$b_{\max }$ & 50 \\
$b_{\min }$ & 0 \\
$f_{\max }$ & 100 \\
$f_{\min }$ & 0.001 \\
\hline
\end{tabular}

\section{Conflict of Interests}

The authors declare that there is no conflict of interests regarding the publication of this paper.

\section{Acknowledgments}

This study was funded by the Project (no. 2008AA092301) supported by the National High Technology Research and Development Program of China and the Program for Zhejiang Leading Team of S\&T Innovation (no. 2010R50036). The authors thank the anonymous reviewers for their detailed and valuable comments, which strengthened this paper.

\section{References}

[1] J. Whatton, Fluid Power Systems, Prentice Hall, 1989.

[2] H. E. Merrit, Hydraulic Control Systems, Willey, New York, NY, USA, 1967.

[3] S. D. Shi, Submarine Controllability, National Defence Industry Press, 1995.

[4] C. X. Wang, Hydraulic Control System, Machinery Industry Press, 2004.

[5] Z. L. Wang, Modern Electric Hydraulic Servo Control, Beijing University of Aeronautics and Astronautics Press, Beijing, China, 2005.

[6] P. M. FitzSimons and J. J. Palazzolo, "Part I: modeling of a onedegree-of-freedom active hydraulic mount," Journal of Dynamic Systems, Measurement and Control, vol. 118, no. 3, pp. 439-442, 1996.

[7] P. M. FitzSimons and J. J. Palazzolo, "Part II: control of a onedegree-of-freedom active hydraulic mount," Journal of Dynamic Systems, Measurement and Control, vol. 118, no. 3, pp. 443-448, 1996.

[8] A. Alleyne and J. K. Hedrick, "Nonlinear adaptive control of active suspensions," IEEE Transactions on Control Systems Technology, vol. 3, no. 1, pp. 94-101, 1995.

[9] A. Alleyne, "Nonlinear force control of an electro-hydraulic actuator," in Proceedings of the Japan-USA Symposium on Flexible Automation, pp. 193-200, July 1996.
[10] Q. L. Hu, L. Xu, and A. H. Zhang, "Adaptive backstepping trajectory tracking control of robot manipulator," Journal of the Franklin Institute, vol. 349, no. 3, pp. 1087-1105, 2012.

[11] A. Bateman, J. Hull, and Z. Lin, "A backstepping-based low-andhigh gain design for marine vehicles," International Journal of Robust and Nonlinear Control, vol. 19, no. 4, pp. 480-493, 2009.

[12] J. Fu, T. Chai, C. Y. Su, and Y. Jin, "Motion/force tracking control of nonholonomic mechanical systems via combining cascaded design and backstepping," Automatica, vol. 49, no. 12, pp. 36823686, 2013.

[13] S. H. Park and S. I. Han, "Robust-tracking control for robot manipulator with deadzone and friction using backstepping and RFNN controller," IET Control Theory and Applications, vol. 5, no. 12, pp. 1397-1417, 2011.

[14] K. K. Ahn, D. N. C. Nam, and M. Jin, "Adaptive backstepping control of an electrohydraulic actuator," IEEE/ASME Transactions on Mechatronics, vol. 99, pp. 1-9, 2013.

[15] H. Zeng and N. Sepehri, "Adaptive backstepping control of hydraulic manipulators with friction compensation using LuGre model," in Proceedings of the American Control Conference, pp. 3164-3169, June 2006.

[16] M. Kristic, I. Kanellakopoulos, and P. Kokotovic, Nonlinear and Adaptive Control Design, Wiley, New York, NY, USA, 2005.

[17] J. E. Slotine and W. Li, "Adaptive manipulator control: a case study," IEEE Transactions on Automatic Control, vol. 33, no. 11, pp. 995-1003, 1988.

[18] J.-J. E. Slotine and W. P. Li, Applied Nonlinear Control, Prentice Hall, Eaglewood Cliffs, NJ, USA, 1991.

[19] B. Yao, Adaptive robust control of nonlinear systems with application to control of mechanical systems [Ph.D. thesis], University of California at Berkeley, 1995.

[20] A. Mohanty and B. Yao, "Indirect adaptive robust control of hydraulic manipulators with accurate parameter estimates," IEEE Transactions on Control Systems Technology, vol. 19, no. 3, pp. 567-575, 2011. 


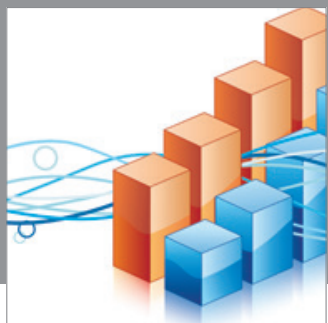

Advances in

Operations Research

mansans

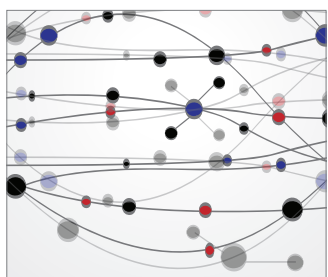

The Scientific World Journal
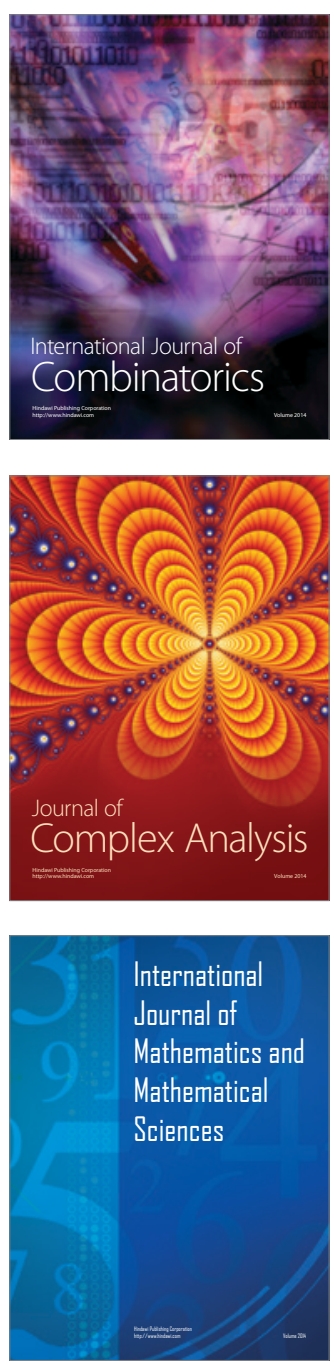
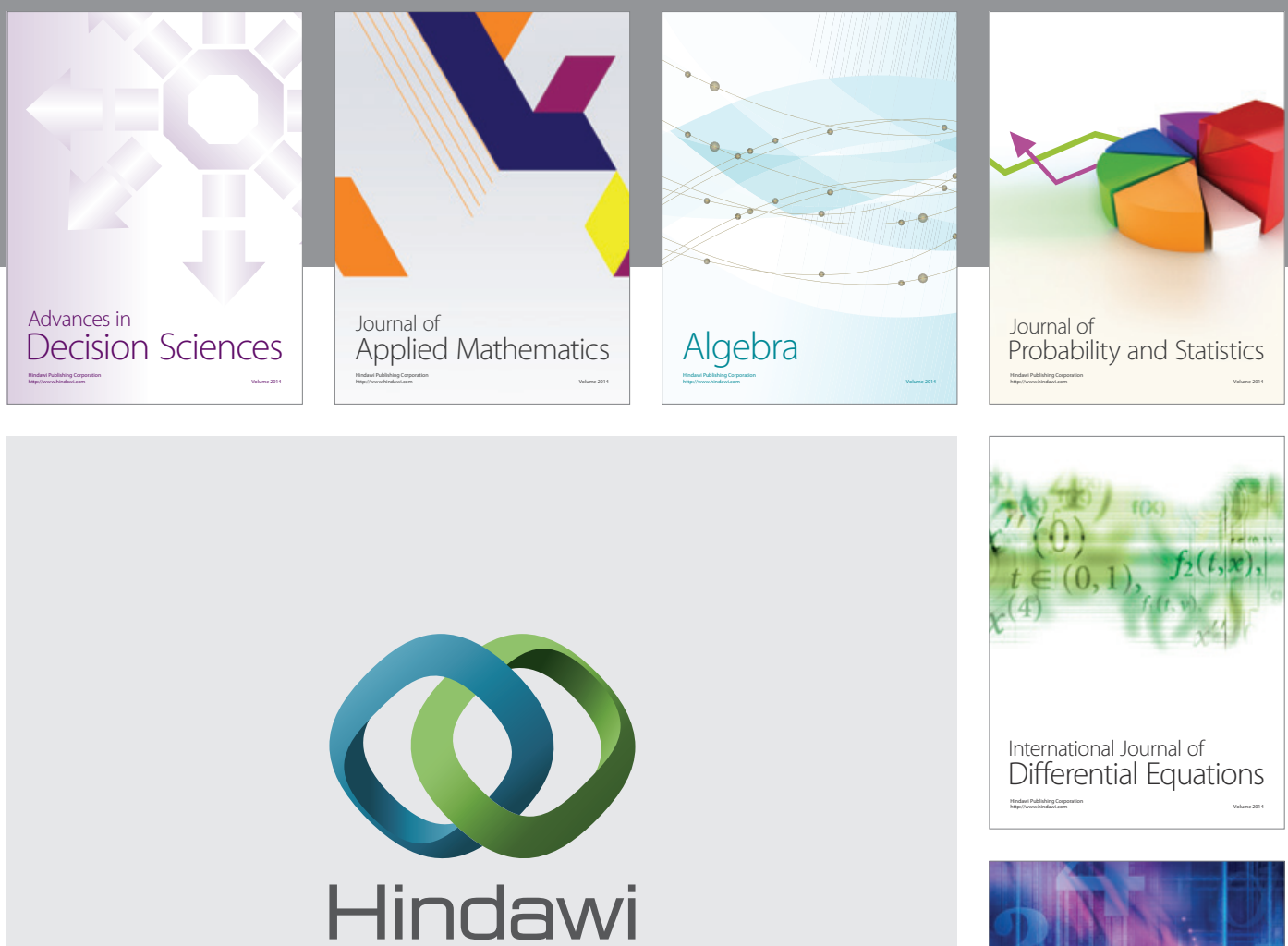

Submit your manuscripts at http://www.hindawi.com
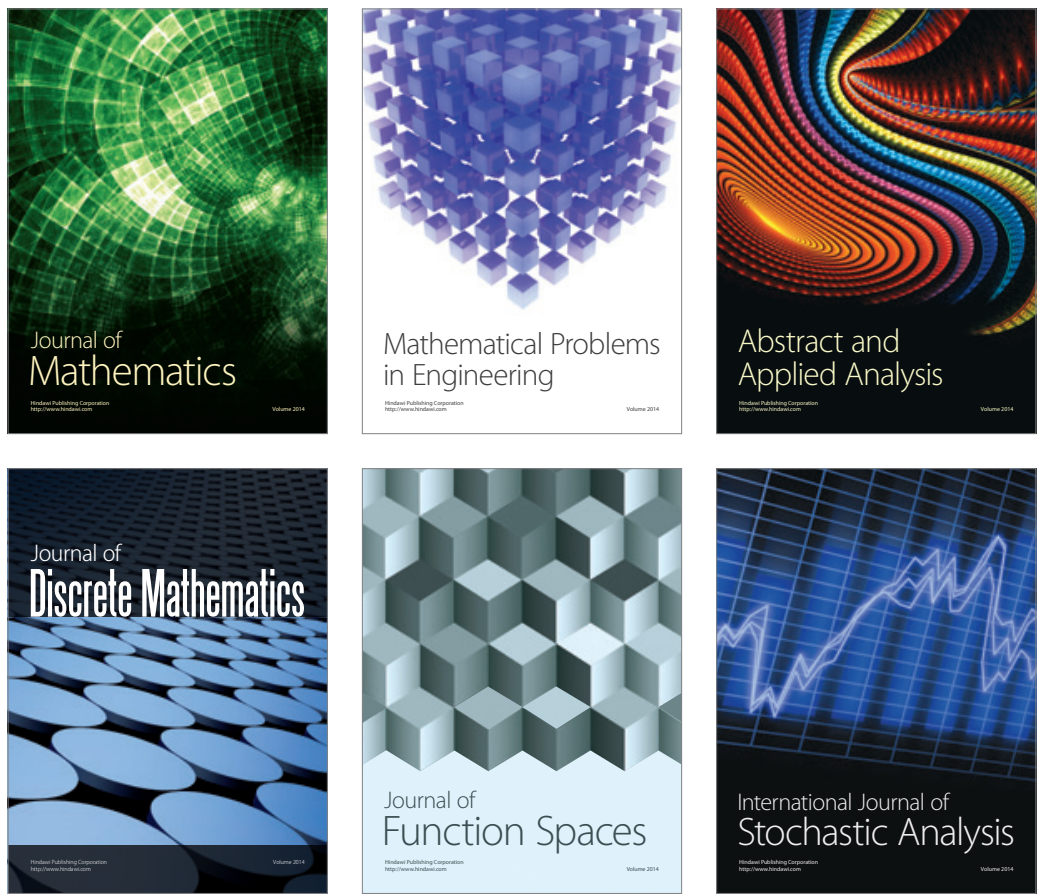

Journal of

Function Spaces

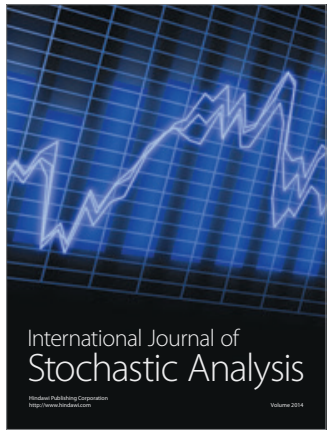

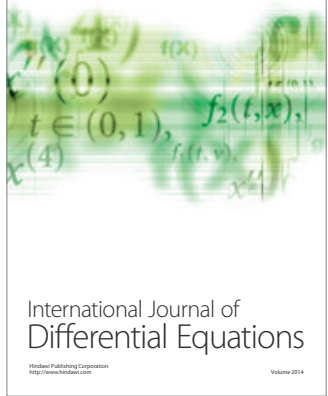
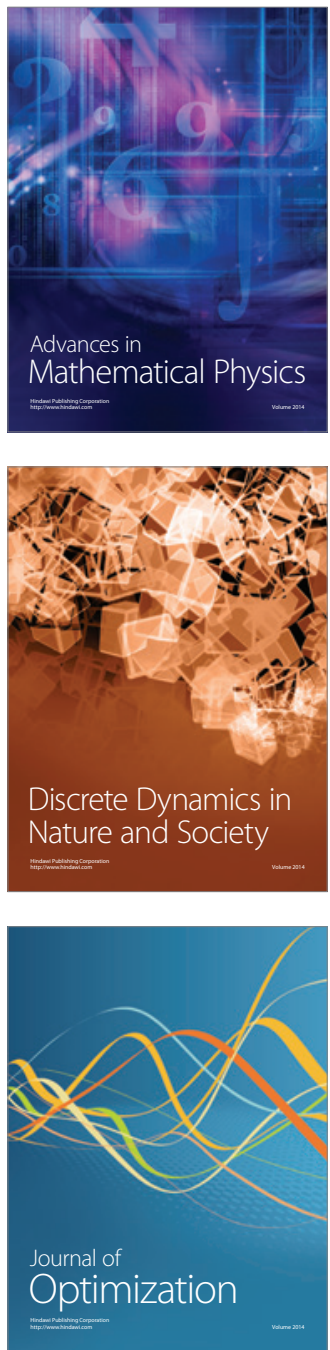